\title{
Direito de família e psicanálise: uma abordagem da alienação parental a partir das fórmulas quânticas da sexuação*1
}

\author{
Family law and psychoanalysis: an \\ approach to parental alienation based on \\ the quantic formulas of sexuation
}

Eduardo Ponte Brandão*2

O objetivo do presente trabalho é demonstrar a contribuição da psicanálise, em especial a partir das fórmulas quânticas da sexuação, para o debate dos problemas de gênero articulado ao tema da alienação parental e, de modo geral, para os impasses provocados pela judicialização das relações familiares. Para tanto, é feita a revisão bibliográfica de autores que demonstram as articulações e as diferenças entre o método e o discurso da psicanálise, de um lado e de outro, o direito de família. Conclui-se que a psicanálise lança luz sobre a tendência do direito, regido pelo universal do gozo fálico, em repudiar a alteridade e a singularidade inscrito no campo do gozo Outro ou gozo feminino.

Palavras-chave: Judicialização, alienação parental, gênero, sexuação

${ }^{* 1} \mathrm{O}$ presente trabalho é resultado de pesquisa de pós-doutoramento realizada através do programa em Psicanálise, Saúde e Sociedade pela Universidade Veiga de Almeida UVA, de 2017 a 2019.

*2 Universidade Candido Mendes - UCAM (Rio de Janeiro, RJ, Brasil). 
O(a) psicólogo(a) que atua a serviço de Varas de Família é normalmente investido da atribuição de fornecer subsídios para a tomada de decisões judiciais referentes a ações, em sua maior parte, de disputa de guarda e de regulamentação de convivência familiar. Uma vez que seja orientado(a) pela psicanálise, é importante que ele(a) se coloque em estado de alerta quanto a um problema que não se encerra nos casos atendidos no judiciário, embora sem dúvida central se apresente de forma mais aguda nas famílias em litígio: a judicialização das relações interpessoais. Sabemos que o direito vem expandido sua capacidade normativa e tornando-se um dos instrumentos privilegiados de regulação da vida social. O enfraquecimento do Estado, a globalização da economia, o desmoronamento das sociedades democráticas, a dissolução entre público e privado, são alguns dos fatores responsáveis, segundo certos autores, pela judicialização da vida humana (Motta, 2007; Lopes, 2005).

\section{Discurso jurídico e discurso psicanalítico}

Nesse contexto de judicialização, é importante assinalar que há uma tensão permanente entre sujeito do inconsciente e sujeito do direito, cujo conceito por si só, vale dizer, condensa algumas contradições (Théry, 2007). Tal tensão torna-se evidente quando nos deparamos com a barreira que a judicialização levanta contra as intervenções do analista. Diante de obstáculos tão poderosos, convém interrogarmo-nos como operar sobre o sujeito do inconsciente num contexto em que as narrativas pessoais são orientadas pela semântica do direito.

A judicialização afasta o sujeito da possibilidade de se apropriar de seu enigma subjetivo, na medida em que ele se 
coloca no lugar de vítima que busca reparação pelo dano supostamente infligido pelo outro e do qual não se vê implicado. Em contrapartida, a psicanálise abre a possibilidade de o sujeito produzir um saber na travessia de suas experiências, logo, de se responsabilizar por seus atos. Dito de outro modo, a judicialização tem como consequência a desresponsabilização do sujeito em relação à desordem da qual se queixa, ao passo que do lado da psicanálise cabe ao sujeito se interrogar sobre sua demanda que, ao ser frustrada, se articula ao seu desejo particular, levando-o a retificar sua posição subjetiva.

A tensão entre direito e psicanálise também se faz sentir em relação ao conceito de verdade, tal como Quinet (2000) aponta a propósito de O seminário sobre 'A carta roubada' (1998c), onde Lacan desenvolve a diferença entre o método de investigação policial e o desvelamento da verdade pela via do significante. No conhecido conto de Edgar A. Poe, os policiais esquadrinham de forma cartesiana o gabinete do ministro em busca da carta roubada, sem encontrá-la, denunciando a "imbecilidade realista" da busca pela exatidão. Por sua vez, Dupin segue as pistas significantes para, então, desvelar o que estava velado, muito embora estivesse à vista de todos. 202 Trata-se da mesma propriedade do sintoma, pois, como diz Quinet (2000): "o sintoma manifesta uma verdade que está na cara, apesar de velada, mas ao ser desvelada jamais é inteiramente apreendida. [...] A radicalidade da não resposta à demanda — daí a frustração - implica no fato de que, no fim das contas, não se tem acesso inteiramente à verdade" (pp. 126-127).

Nessa mesma esteira de discussão, Miranda Junior (2019) aborda, a partir da psicanálise, a verdade no contexto da avaliação psicológica em Varas de Família. Segundo o autor, no discurso jurídico, verdadeiro e falso pressupõem a adequação dos fatos a uma linguagem própria que constitui personagens e narrativas que buscam afetar os julgadores em favor de uma das partes processuais. Donde se reúnem provas dentro dos procedimentos normativos e dos prazos legais para que, ao final, seja feito um julgamento com base na verossimilhança, "ou seja, o que tem a aparência de verdade, o que é plausível, provável” (p. 69). Assim, no campo do direito de família, a tradução de uma experiência subjetiva tem que ter respaldo na lei escrita e se conformar ao trâmite processual para ser considerada válida. "A família que chega ao psicólogo, portanto, é uma família moldada pelo discurso judiciário", escreve o autor "e que apresenta uma demanda ao campo jurídico supostamente padronizada por este mesmo discurso cuja resposta seria capaz de satisfazê-la ou apaziguá-la" (p. 70). 


\section{LITERATURA, ARTE, CULTURA}

Por sua vez, na psicanálise, a verdade é semidita, constituindo-se como efeito de uma experiência na qual se revela a relação do sujeito ao seu desejo e a seu modo de gozo. Consequentemente, o convite para que o sujeito fale sobre as razões que conduziram sua demanda a uma Vara de Família leva-o comumente a falar do amor e do desamor, o que indica a sua posição no desejo do Outro, assim como o seu modo de gozo. Tal orientação explica-se pelo fato de que o fim de um relacionamento amoroso atualiza as perdas que constituíram a historicidade de cada sujeito, por meio das quais são criadas ficções na tentativa de dar conta de sua falta fundamental, de sua falta-a-ser. Seguindo esse raciocínio, o autor assinala que na lida com famílias no tribunal:

[...] se nos dispomos a escutar a partir de uma referência distinta daquela que a instituição nos coloca, podemos servir de suporte para que algo do desejo seja tocado e com isso abrir a possibilidade de vacilação e modificação do sofrimento de quem nos chega enredado nas tramas do sintoma. (Miranda Junior, 2019, p. 87)

Nunes e Penna (2019) apontam para perspectiva semelhante ao assinalarem que cabe ao "especialista" na cena jurídica desconstruir as concepções moralizantes sobre a família, cuja generalização difere muito da realidade de cada uma delas, sempre únicas. Os discursos sobre a família no campo da assistência social em interface com o judiciário, apoiam-se em um imaginário constituído por padrões familiares e ideais da boa mulher mãe e do bom homem pai. Com efeito, a rede de assistência e justiça costumam nomear as famílias em situação de vulnerabilidade, lançando mão de ficções carregadas de preconceitos e julgamentos:

[...] as famílias chegam aos serviços sem voz; chegam "faladas" pelo Outro da justiça. São nomeadas "desestruturadas", "negligentes", "violadoras". Os sujeitos pais e mães são descolados desses significantes e passam a ser chamados "genitor e genitora". (Nunes \& Penna, 2019, p. 93)

O princípio do 'melhor interesse da criança' pode servir de instrumento para separar e remodelar as famílias, cujo destino é colocado nas mãos das instituições. Com base nesse princípio, as decisões judiciais podem fragmentar e recompor uma família, ou até mesmo agrupar uma nova família (por exemplo, em caso de adoção), o que faz indagar se a intervenção judicial pode realmente produzir uma família. Em resposta, Nunes e Penna (2019) argumentam que, ao contrário da regulação externa imposta sobre a família, o psicanalista considera intransferível a implicação de cada sujeito. Desse 
modo, a intervenção analítica possibilita que o sujeito busque o singular de sua constituição familiar, cuja tarefa não é aliviada pela ficção jurídica. $\mathrm{O}$ próprio sujeito terá a tarefa de constituir sua família, sendo aquela que institui a distribuição dos nomes [funções] do pai e da mãe:

As intervenções judiciais não teriam em si o efeito de inscrever psiquicamente as funções parentais - algo que só pode ser balizado na escuta do caso a caso. $\mathrm{O}$ que não quer dizer que a sentença judicial seja sem efeitos. Ao se deparar com a delimitação de uma família pela via jurídica, o sujeito é confrontado com um real com o qual terá que se haver e que lhe convocará à invenção de uma resposta. (Nunes \& Penna, 2019, p. 99)

Por fim, citemos a pesquisa realizada por Dias (2020) sobre as ações judiciais que envolvem acusações de alienação parental, das quais ela extrai trechos dos autos processuais cujas narrativas são marcadas por perspectivas "patologizantes, naturalizantes, criminalizantes e vitimizantes que se articulam como vetores de normalização da família" (p. 68; grifo da autora). Desse modo, as apreciações feitas a respeito de mães e pais vistos como alienadores não são das mais elogiosas: "ansiosos, egocêntricos, agressivos, instáveis, controladores, apresentando muitos casos de personalidade perver$s a$ ", com "ciúmes patológicos", sem escrúpulos e vingativos, sendo ela ou ele "pessoa mentalmente desequilibrada, dissimulada", a ponto de ser sugerido "exame psiquiátrico para apurar a sua sanidade mental" (Dias, 2020, pp. 71-78; grifo da autora).

Nesse contexto beligerante de Varas de Família, a autora observa a preponderância de ações de alienação parental contra as mulheres, por um lado e, por outro lado, de ações de indenização por abandono afetivo contra os homens. Enquanto as primeiras denunciam as mães pela dominação do exercício parental, as segundas versam sobre o distanciamento afetivo dos pais, ainda que as obrigações alimentícias sejam cumpridas. Nessa distinção de gênero, percebe que a função de provedor sobressai em relação aos homens, sendo que, quando acusados de alienação parental, atribui-se um abuso "da força econômica" destes sobre os filhos. As mulheres costumam queixar-se de forma recorrente de uma paternidade lúdica, exercida apenas em horas de lazer, sublinhando o desinteresse pelas questões substanciais da parentalidade.

Por sua vez, as suposições judiciais sobre as motivações da alienação atribuída às mães dividem-se entre a retaliação pela insatisfação quanto aos valores da pensão alimentícia, e "uma vingança dirigida ao outro, "movida pelo rancor [...] em decorrência da sua decisão de pôr fim ao relacionamento afetivo', na qual se acentuam as desqualificações da mulher e da mãe em 


\section{LITERATURA, ARTE, CULTURA}

virtude de sua natureza passional" (Dias, 2020, p. 80). Nesse caso, as ações judiciais normalmente destacam o poder nocivo da afetividade materna, cujas queixas ora se dirigem contra os excessos da influência da mãe sobre os filhos, ora contra um suposto exercício incompetente e desequilibrado da maternidade.

Dias (2020) conclui que a judicialização que atinge não somente as mulheres, mas todos os envolvidos na lide familiar, encontra abrigo no Discurso do Capitalista na medida em que aciona um circuito insaciável de objetos que encobre a verdade sobre a falta do sujeito. Nesse domínio a judicialização pressupõe a intolerância com a falta e a radical diferença do outro, propondo soluções que afastam o sujeito de sua responsabilidade. Seguindo esse raciocínio:

A justiça (S1), articulada ao saber científico (S2), propõe tratar o mal-estar do sujeito em conflito nos laços familiares através da Lei da Alienação Parental, que estabelece medidas para remediar o problema. O que não está posto para os sujeitos litigantes é que a sentença, apesar de poder comportar um efeito terapêutico, por si só não é capaz de suturar o mal-entendido estruturante do laço, que demanda maleabilidade e criatividade. (Dias, 2020, pp. 94-95)

Feita essas distinções entre o direito e a psicanálise, no que tange à verdade, demanda, sujeito etc., é importante destacar que a judicialização não é exclusividade das famílias em litígio, pois se inscreve no cenário contemporâneo das novas formas de organização de família e de conjugalidade, bastante distintas do modelo familiar pequeno-burguês valorizado na aurora da modernidade. Nesse sentido, Birman (2007) afirma que as modalidades de experiência subjetiva têm relação crucial com as formas de organização da família. Sendo assim, as mudanças político-sociais ocorridas nas últimas décadas (emancipação feminina, mono e homoparentalidade, escolarização da primeira infância) tiveram como consequência a substituição das neuroses clássicas, descritas por Freud, por outros tipos de padecimento:

As neuroses clássicas se tornam hoje cada vez mais rarefeitas na demanda de cuidados, à medida que a conflitualidade psíquica se dilui de forma progressiva e significativa. A conflitualidade interior é cada vez mais substituída pelos embates que se estabelecem entre os indivíduos e destes com as instâncias exteriores, no campo social e interpessoal. (Birman, 2007, p. 48)

Diante desse panorama teórico, convém perguntarmo-nos: hoje em dia as experiências de dor e sofrimento são encaminhadas com mais frequência do que outrora ao judiciário em vez de para a clínica? Os conflitos do par 
familiar diante dos impasses da vida amorosa e do exercício próprio da parentalidade, cujos desdobramentos se articulam nos sintomas infantis, não são hoje em dia endereçados ao judiciário com mais frequência do que outrora?

Por fim, a judicialização está em pauta quando abordamos dois temas que atualmente possuem proporções gigantescas nas Varas de Família, ao mesmo tempo em que correspondem a expressões de sofrimento da criança em situação de litígio familiar: a alienação parental e o abuso sexual.

\section{Alienação parental, abuso sexual e gênero}

Alienação parental e abuso sexual costumam ser colocados em dicotomia de tal maneira que, no campo das práticas jurídicas, a não confirmação do abuso sexual intrafamiliar, cuja suspeita é frequentemente levantada pela mãe contra o pai, pode se reverter contra ela como acusação de alienação parental. Em geral, no contexto dos litígios familiares, quando ocorre uma acusação de abuso sexual, o homem, mais precisamente o pai, busca inverter o trajeto das acusações e da vitimização. Segundo Oliveira (2019), as acusações de abuso sexual contra crianças e adolescentes não costumam prosperar como tal nas camadas médias e, quando ocorrem, a nebulosidade nas narrativas e nos depoimentos, as contradições, a ausência ou falta de provas conclusivas dificulta a capacidade decisória do juiz, cuja resolução é encontrada na medida em que se lança mão da alienação parental. Com efeito, para a autora, alienação parental e abuso sexual são "como os dois lados de uma moeda cujo valor é sustentado por fortes asserções morais acerca do modo de organizar emoções, afetos e comportamentos no interior da família" (Oliveira, 2019, p. 168).

Existem razões históricas pelas quais alienação parental e abuso sexual são equacionados em sentidos contraditórios, tendo como pano de fundo a política de gêneros (Brandão, 2019a; 2019b). A promulgação da lei da alienação parental decorreu em boa parte da pressão de grupos de pais separados por direitos iguais aos das mães, correspondendo a uma construção ideológica sem suporte na realidade das vidas familiares e da divisão desigual do trabalho entre os sexos (Devreux, 2006). Nesse contexto, a teoria de Richard Gardner, psiquiatra norte-americano criador do conceito de síndrome de alienação parental, visava transformar em patologia o exercício de direitos legais por parte da mulher que, em muitas situações, defende os seus filhos. Ao situar a falsa denúncia de abuso sexual como sendo uma das 


\section{LITERATURA, ARTE, CULTURA}

manifestações mais graves de alienação parental, Gardner parte da presunção de que, ao suspeitar que o filho sofreu abuso sexual da parte do pai, a mãe age de má fé (Sottomayor, 2011).

O campo de batalha entre gêneros é, portanto, ofuscado nos discursos e nas práticas que giram em torno da alienação parental, assim como da guarda compartilhada. A teoria da alienação parental tem, segundo Sottomayor (2011), "um significado ideológico muito claro: a menorização das crianças e a discriminação de gênero contra as mulheres" (p. 75).

Acredito que uma das expressões da misoginia reside na intolerância de certos homens frente às mulheres dos quais se divorciam e que, após a separação, procuram se desvencilhar do papel de esposa e mãe a que eram destinadas. Não são raros os ataques à moral sexual da mulher nos litígios de família por não corresponderem aos ideais de amor materno. Donde deduzimos que as expressões de feminilidade são, via de regra, repudiadas quando despontam no campo da maternidade, impondo-se como suposta ameaça à ordem familiar pequeno-burguesa tradicional, formada pela matriz monogâmica e heterossexual.

Alguns autores favoráveis à teoria de Richard Gardner argumentam que o viés misógino foi superado pelo próprio autor no início dos anos 2000 quando, após pressões de feministas, reformulou a definição original e conferiu gênero neutro ao "agente alienador". Contudo, o tempo maior que as mães costumam passar com a prole e o vínculo primário entre elas e o bebê faria com que a alienação prevalecesse do lado materno do que paterno, cujo quadro, segundo o autor, se modificaria na medida em que evoluísse a igualdade entre os gêneros (Brockhausen, 2019).

Nesse panorama teórico, convém lembrar que "gênero" é um termo criado por movimentos feministas com objetivo de refutar explicações de fundo biológico para as diferenças atribuídas a homens e mulheres. Assim, desde os primeiros trabalhos feministas, o gênero configurou-se como um conceito relacional que enfatiza o caráter social das distinções baseadas no sexo.

Contudo, a dimensão biológica permanecia intocada nos debates feministas até o surgimento da teoria queer. A partir de então, em vez de pensar o gênero como uma construção sociocultural baseada no sexo, como se este último correspondesse a um estado da natureza, portanto fora da cultura, a teoria queer inverte essa lógica e demonstra que o sexo é uma produção discursiva subordinada a uma organização normativa de gênero, via de regra de caráter hierárquico, assimétrico e binário. Para Butler (2012), o gênero 
deve ser analisado de acordo com uma "matriz de inteligibilidade" (p. 39), constituída pelos termos gênero, sexo e desejo sexual/práticas sexuais, cuja organização pode resultar em identidades aceitáveis culturalmente, e outras não. Os arranjos não tolerados evidenciam o limite de práticas reguladoras que estabelecem regras heteronormativas de gênero e de sexo.

Assim, o conceito de igualdade parental que se encontra tanto na base da teoria da alienação parental quanto da concepção de guarda compartilhada ofusca a matriz heteronormativa que destina homens e mulheres a enlaces conjugais, práticas e desejos sexuais, cuidados e responsabilidades paternos e maternos, traições e desilusões amorosas, rupturas da união conjugal, inserção e colocação no mercado de trabalho, manutenção financeira durante o casamento e no pós-divórcio, entre outros fatores, de forma diferenciada. Há uma irredutível tensão entre conjugalidade e parentalidade que deve ser levada em consideração nesse grande debate que envolve os litígios familiares.

Ainda assim, haverá quem diga que, a bem da verdade, a lei da alienação parental se aplica aos casos em que a criança repudia injustificadamente a sua mãe. Dessa maneira, o pai é visto como alienador cuja situação, mesmo 208 não correspondendo à maior parte dos casos, não são pouco numerosos: “[...] existem casos em que o homem é a figura alienadora e a mulher se beneficia da lei. Importante destacar que Gardner dedica parte do seu livro para descrever a alienação parental praticada por homens" (Brockhausen, 2019, p. 126).

$\mathrm{Na}$ tentativa de ultrapassar esse impasse, convém deslocarmo-nos do prisma da política de gêneros para uma abordagem psicanalítica, mais precisamente, a partir da dialética do desejo e do gozo que enlaça o par familiar e a criança.

\section{As fórmulas quânticas da sexuação}

Para tanto, convém debruçarmo-nos sobre as fórmulas quânticas de sexuação, desenvolvidas por Lacan nos anos 1970, por meio das quais ele realiza a partilha entre os sexos segundo duas posições diferentes de gozo masculino e feminino, respectivamente, fálico e não todo fálico. A partilha entre masculino e feminino corresponde a posições passíveis de serem ocupadas tanto por homens quanto por mulheres, observando, conforme Lacan formula em seu conhecido axioma - A Mulher não existe -, que não existe ninguém que frequente exclusivamente o campo do feminino e 


\section{LITERATURA, ARTE, CULTURA}

sim que homens e mulheres necessariamente frequentam o campo do gozo fálico.

Até então, Lacan diferenciava a posição masculina e feminina a partir da dialética fálica, tendo como pressuposto que há apenas um significante, o falo, para designar os dois sexos. Com efeito, em "A significação do falo" (1958/1998a), Lacan destaca que o complexo de castração tem como função, para ambos os sexos, instalar no sujeito uma posição inconsciente que abre a possibilidade de se identificar com o tipo ideal de seu sexo para além de sua anatomia, responder sem perturbações às necessidades do parceiro, cujo termo necessidade será substituído depois por desejo, e se referir à paternidade ou maternidade não no sentido biológico. Tais aspectos — identificar-se como homem ou mulher, responder ao desejo do parceiro amoroso e acolher as necessidades da criança - dependem, portanto, do falo, designado por Lacan como significante da falta, que, distinto do órgão anatômico, implica a perda de gozo que incide sobre ambos os sexos.

Porém, na mesma época de "A significação do falo", embora em outro texto, "Diretrizes para um congresso sobre a sexualidade feminina", Lacan (1960/1998b) interroga-se "se a mediação fálica drena tudo o que pode se manifestar de pulsional na mulher, notadamente toda a corrente do instinto materno" (p. 739), abrindo caminho para suas construções posteriores a respeito do gozo feminino que serão desenvolvidas nos anos 1970, conforme dito acima, em especial no Seminário 20, Mais ainda, e no texto "O aturdito".

Ao formular a partilha dos sexos através de duas posições distintas de gozo, Lacan aponta para um gozo além da mediação fálica, correspondendo ao gozo feminino. Assim, o sujeito orienta-se com relação ao gozo para além do Um que se agrupa através do falo. Em outras palavras, o feminino rompe com o universal da função fálica, expressando-se pela escrita do não todo.

Enquanto o sujeito inscrito no campo do masculino pode ser tomado como exemplo particular do conjunto, por estar todo inscrito no gozo fálico, o sujeito situado no gozo feminino deverá ser tomado no singular. Se no campo do masculino, o sujeito se especifica por manter uma relação com o gozo estritamente no campo limitado do falo, por sua vez, o sujeito posicionado no feminino frequenta não só o gozo fálico, mas um além dele denominado de gozo do Outro, ilimitado, um gozo suplementar.

Não há relação sexual entre o gozo masculino e o gozo feminino, podendo se realizar tão somente o encontro entre eles. Dessa maneira, a relação sexual é possível somente no campo da fantasia, sendo uma invenção de cada sujeito para fazer face à inexistência da relação sexual 
(Lacan, 1972-73/1985). Portanto, sem que haja complementaridade entre os sexos, o sujeito situado no campo do gozo masculino faz da 'mulher' seu sintoma, inscrevendo-a do lugar de objeto $a$, ao mesmo tempo em que 'ela' lhe dá signos do inconsciente do sujeito que a elegeu. Por sua vez, o sujeito que circula do lado feminino encontra o significante de seu desejo no corpo 'daquele' que a elegeu, ou seja, se reconhece como 'faltosa' e endereça a um 'homem' o significante que lhe falta.

Cabe fazer aqui a ressalva de Quinet (2019) quanto a duas versões sobre as fórmulas da sexuação.

$\mathrm{Na}$ primeira versão, os seres humanos distribuem-se em dois campos distintos, fálico e não todo fálico, e a partir deles o sujeito se propõe ser dito'homem', de um lado e, de outro lado, o sujeito se propõe ser dito 'mulher'. "Há uma identificação e uma modalidade própria de gozo aos falasseres que estão do lado do todo fálico e outra do lado do não todo" (Quinet, 2019, p. 34), sendo as duas posições sustentadas pela não relação sexual.

Na segunda versão, as fórmulas da sexuação correspondem a diferentes posições que um mesmo sujeito pode tomar independentemente de seu sexo, gênero ou orientação sexual. Há uma plasticidade sexual que permite o sujeito circular por todas as posições: sujeito, objeto, falo e A mulher que não existe. Portanto, seja macho ou fêmea, o sujeito situado do lado do todo fálico pode ocupar a posição do sujeito desejante e de falo e, assim, reduzir o(a) parceiro (a) sexual para gozar dele ou dela como objeto ou, ainda, sustentar o falo cujo brilho atrai aquele ou aquela que está no lugar de A mulher que não existe. Por outro lado, o sujeito — macho ou fêmea — também pode se situar como objeto causa de desejo e "ocupar o lugar de A mulher que não existe atraído pela posição fálica da parceira ou do parceiro" (Quinet, 2019, pp. 35-36). Em resumo, machos e fêmeas humanas podem circular pelo lado do todo e não todo fálico, mesmo que haja fixações numa dada posição sexuada ou que façam tal ou tal semblante de gênero.

Acreditamos que as duas versões não sejam incompatíveis, mas de qualquer maneira, a segunda versão atende melhor ao objetivo de contornar o impasse acima sobre a questão do gênero nos litígios familiares, com ênfase na alienação parental. Compreendemos, assim, que nos torneios amorosos do casal, e também par familiar, que são marcados por desilusões, traições, reaproximações frustradas e rupturas violentas do enlace amoroso que, inclusive, continuam a ocorrer no pós-divórcio, os sujeitos possam circular e até mesmo alternar entre as diferentes posições sexuadas, independentes de 


\section{LITERATURA, ARTE, CULTURA}

serem machos ou fêmeas, genitores masculinos ou femininos. Nesse jogo de encontro e desencontro de desejos e de gozos, o real da não relação sexual se mostrará presente como aquilo que não cessa de não se escrever, frente ao qual a criança responderá com seu sintoma. Desse modo, em articulação ao seu sintoma, o ódio destinado a um dos genitores pode se encaminhar tanto contra o seu pai quanto à sua mãe.

Todavia, não pretendo aqui lançar mão de generalizações a respeito do ódio que a criança dirige ao pai, algo tão estruturante para a subjetividade humana, apesar de interpretado no contexto da judicialização como expressão de alienação parental. Digo, estruturante, considerando a gênese do Supereu como instância herdeira da dialética edipiana, sendo a hostilidade contra o pai uma de suas marcas essenciais.

O ponto a que pretendemos chegar é a hipótese de que o direito enquanto teoria da soberania se organiza através da lógica fálica e, portanto, recusa o gozo não todo fálico, na medida em que subverte a sua ordem. A semântica da alienação parental pode ser expressão de repúdio à alteridade singular, característica do gozo feminino, não todo fálico, o que explicaria a misoginia assinalada acima através da leitura crítica de gênero.

Na tábua da sexuação, Lacan escreve do lado masculino as fórmulas: "existe ao menos um homem para quem a função fálica não incide" e "para todo homem é verdadeiro que a função fálica incide". A primeira delas foi baseada no mito do pai da horda primitiva, apresentado por Freud em "Totem e tabu" (1913/1996), cujo assassinato é seguido pela instauração da lei do interdito do incesto, portanto, como dirá Lacan em seu retorno aos textos de Freud, da Lei simbólica. Na fórmula lacaniana, a função fálica $(\Phi x)$ remete à castração que tem um traço horizontal sobre ela, indicando a sua negativa. Desse modo, a fórmula de que "existe pelo menos um homem que não foi submetido à castração" remete ao pai primevo, ou seja, este pelo menos um que não segue a regra da castração, cuja exceção funda a Lei. A universalidade expressa na segunda fórmula só tem sentido, portanto, porque pelo menos um elemento se subtrai dela. A linha inferior do lado masculino assim se resume, trazendo a fórmula proposicional que ilustra essa universalidade: "para todo homem é verdadeiro que a função fálica incide".

O lado masculino corresponde à lógica do Um, do universal, onde podemos inscrever o campo do Direito. O ordenamento jurídico organiza-se em uma unidade, cuja espinha dorsal está centrada, como bem demonstra Barros (2001), no poder paterno. Apela-se ao pater familias para justificar a fonte das fontes, e quando a referência passou a se mostrar ausente na realidade, 
os autores ligados à filosofia do Direito apelam para a ficção, encontrando a palavra do pai, a metáfora paterna, em seu fundamento.

Do lado feminino, Lacan escreve as formulações: "não existe ao menos uma mulher para quem a função fálica não incide" e "para não toda mulher é verdadeiro que a função fálica incide". Na primeira proposição, ele demonstra que não existe ao menos uma mulher que seja uma exceção à regra, de modo que, sem a exceção, não existe a regra universal para todas as mulheres. Se a exceção funda a regra, com a ausência de uma exceção, a universalidade, (x), o 'para todo $x$ ' não se aplica. Como vimos do lado masculino, o conjunto universal só pode ser fundado na presença de um que esteja fora da regra do 'todo'. Assim, se do lado feminino não há essa exceção, a universalidade do ponto de vista da função fálica torna-se inviável. Ou seja, é impossível falar de 'todas as mulheres' e não haveria "A Mulher", numa categoria universal afirmativa, donde se produzem as famosas frases "A Mulher não existe" e "a mulher é não toda".

Sobre o feminino, é importante destacar que a psicanálise surgiu diante de uma particular manifestação do feminino, a histeria, que denunciava a castração do mestre ao fazer furo no campo do saber da medicina. Ao colocar 212 as histéricas no centro da cena analítica, Freud abriu uma via inédita ao real do inconsciente e deu uma inestimável contribuição para a retirada das mulheres dos bastidores do campo sociopolítico que marcou o século XX, num contexto de época em que declinavam os semblantes da autoridade patriarcal ao mesmo tempo que novas formas de família e da sexualidade já começavam a dar seus primeiros sinais (Fuentes, 2012).

Passado mais de um século, observamos que apesar de a síndrome de alienação parental não ter sido incorporada como tal pelos manuais diagnósticos, a sua concepção pelo psiquiatra norte-americano fez com que ela fosse portadora dos signos da ciência médica suficientes para serem absorvidos pelo campo do direito (Dias, 2020). Com efeito, a mãe-mulher transformou-se no alvo principal das controvérsias judiciais, sendo classificada amiúde de sedutora, manipuladora e mentirosa, cujas características nada ficam a dever ao modo como as histéricas eram concebidas antes de Freud conceder-lhes a fala.

Donde convém perguntar se as mulheres-mães criticadas como alienadoras não seriam aquelas que, tal como as histéricas, apontam para o furo do saber do direito que, como vimos, costuma ser embalado pelos ideais idílicos de família. Não será a porção mulher que habita a mãe que se torna tão insuportável para aquele (ou aquela) que ocupa o lado masculino, contra a qual 


\section{LITERATURA, ARTE, CULTURA}

ele (ou ela) recorre ao aparato jurídico que, igualmente, não tolera a presença desse gozo não todo? Não seriam os excessos do gozo feminino que desafiam a ordem fálica, contra os quais os tribunais de justiça se colocam na tentativa de freá-lo ou, ao menos, fazer suplência à Lei simbólica?

De todo modo, numa parte significativa dos discursos jurídicos que giram em torno da alienação parental, percebemos uma cruzada contra o gozo feminino presente na mãe-mulher. A recusa do gozo feminino parece nutrir o ideal da mãe amorosa, cujo elemento compõe o sonho do direito de que a criança terá amor e respeito por seu pai sem contribuir com sua parcela de gozo.

\section{Conclusão}

A alienação parental é hoje em dia um dos temas predominantes nas ações judiciais de litígio familiar, tendo como base o direito inalienável à convivência familiar da criança e do adolescente e o ideário de igualdade parental, ressalvando que este último ofusca um amplo debate sobre a desigualdade de gêneros. Com efeito, o conceito de alienação parental, oriundo das teorias de Richard Gardner sobre a Síndrome de Alienação Parental, é alvo de críticas por autores feministas que identificam em seu bojo uma forte misoginia com reflexos práticos nos atos processuais e decisórios no campo do judiciário e da assistência. Em contrapartida, conforme exposto acima, autores defensores da alienação parental argumentam que a lei pode proteger casuisticamente mulheres vítimas da influência de ex-parceiros sobre sua prole, de tal modo que nem a legislação, tampouco a teoria de Gardner, podem ser acusadas de sexista e misógina.

$\mathrm{Na}$ tentativa de superar esse imbróglio, a abordagem psicanalítica sobre a dialética do desejo e dos gozos com base nas fórmulas quânticas da sexuação proporciona importantes contribuições ao debate. A partir delas, identificamos que, no contexto de judicialização da qual a alienação parental é um dos seus emblemas, há uma recusa do gozo feminino, cujo campo pode ser frequentado por homens e mulheres, independente do gênero. $\mathrm{O}$ campo do direito organiza-se através do universal do gozo todo fálico, masculino, e, portanto, procura manter à distância a singularidade que se inscreve do lado do gozo não todo fálico.

É importante destacar que a alienação parental é um tema controverso que se encontra na ordem do dia e vem suscitando amplos debates no 
Congresso Nacional, inclusive, com base nos projetos de lei $\mathrm{n}^{\circ} 6371 / 19^{1}$ ou $n^{\circ} 498$, de $2018,{ }^{2}$ os quais pretendem revogar ou alterar os termos da lei 12.318/10 (lei da alienação parental), reunindo grupos de pressão favoráveis e contrários ao tema. Se por um lado há grupos de pressão de mulheres que perderam a guarda dos filhos em favor dos homens a quem elas haviam acusado de abusadores e, assim, querem a revogação da lei, por outro lado há grupos de pressão que querem medidas mais duras, inclusive, com penas criminais, contra os atos de alienação parental.

A controvérsia em torno da alienação parental culminou, inclusive, numa publicação pelo Conselho Federal de Psicologia dedicada ao tema, expondo as posições divergentes de psicólogos a esse respeito. ${ }^{3}$ Parte dos argumentos apresentados em tal documento foram utilizados no presente ensaio, buscando a interlocução com a psicanálise.

Ao expormos uma visão crítica à luz da psicanálise, não pretendemos aqui, entretanto, simplesmente endossar a revogação da lei, tampouco expor suas brechas de modo que ela possa ser aperfeiçoada. A controvérsia legislativa que reúne profissionais do direito, da psicologia, entre outros, em favor ou contra a lei da alienação parental não ultrapassa a lógica 214 da judicialização das relações humanas, cujos efeitos subjetivos foram explorados neste ensaio. Ao contrário do discurso jurídico, acreditamos que a psicanálise abre um continente de escuta para que os sujeitos envolvidos em situação de dor e sofrimento psíquico, enredados num conflito familiar, sejam capazes de ressignificar suas posições subjetivas em relação às demandas endereçadas ao judiciário.

\section{Referências}

Barros, F. (2001). Do Direito ao Pai. Belo Horizonte, MG: Del Rey.

Birman, Joel. (2007). Laços e desenlaces na contemporaneidade. Jornal de Psicanálise, 40(72), 47-62. Recuperado em 22 abr. 2020, de http://pepsic.bvsalud. org/scielo.php?script=sci_arttext\&pid=S0103-58352007000100004\&lng=pt\&tln $\mathrm{g}=\mathrm{pt}$.

${ }^{1}$ https://www.camara.leg.br/noticias/631131-projeto-revoga-a-lei-de-alienacao-parental/

${ }^{2}$ https://www25.senado.leg.br/web/atividade/materias/-/materia/134835

${ }^{3}$ https://site.cfp.org.br/publicacao/debatendo-sobre-alienacao-parental-diferentes-perspectivas/ 


\section{LITERATURA, ARTE, CULTURA}

Brandão, E. (Org.). (2019a). Psicanálise e Direito: subversões do sujeito no campo jurídico. Rio de Janeiro, RJ: Nau.

Brandão, E. (2019b). Os problemas de gênero na Alienação Parental e na Guarda Compartilhada. In Conselho Federal de Psicologia, Debatendo sobre alienação parental: diferentes perspectivas (pp. 173-184). Brasília, DF: CFP.

Brockhausen, T. (2019). Retrospectiva da Lei de Alienação Parental. In Conselho Federal de Psicologia, Debatendo sobre alienação parental: diferentes perspectivas (pp. 116-133). Brasília, DF: CFP.

Butler, J. (2012). Problemas de gênero: feminismo e subversão da identidade (4a ed.) Rio de Janeiro, RJ: Civilização Brasileira.

Devreux, A.-M. (2006). A paternidade na França: entre igualização dos direitos parentais e lutas ligadas às relações sociais de sexo. Sociedade e Estado, 21(3), 607-624. https://doi.org/10.1590/S0102-69922006000300003.

Dias, J. (2020). Filhos entre laços familiares judicializados: uma leitura psicanalítica sobre o fenômeno da alienação parental. (Dissertação de Mestrado), Universidade Federal da Bahia, Salvador, BA.

Freud, S. (1996). Totem e tabu. In Edição Standard Brasileira das Obras Psicológicas Completas de Sigmund Freud. Rio de Janeiro, RJ: Imago. (Trabalho original publicado em 1913).

Fuentes, M. J. (2012). As mulheres e seus nomes: Lacan e o feminino. Belo Horizonte, MG: Scriptum.

Lacan, J. (1998a). A significação do falo. In Escritos (pp. 692-703). Rio de Janeiro, RJ: Jorge Zahar. (Trabalho original publicado em 1958).

Lacan, J. (1998b). Diretrizes para um congresso sobre a sexualidade feminina. In Escritos (pp.734-745). Rio de Janeiro, RJ: Jorge Zahar. (Trabalho original publicado em 1960).

Lacan, J. (1998c). O Seminário sobre 'A carta roubada'. In Escritos (pp. 13-68). Rio de Janeiro, RJ: Jorge Zahar.

Lacan, J. (1985). O seminário. Livro 20. mais ainda. Rio de Janeiro, RJ: Jorge Zahar. (Trabalho original publicado em 1972-73).

Lopes, J. (2005). A Invasão do Direito: a expansão jurídica sobre o estado, o mercado e a moral. Rio de Janeiro, RJ: FGV.

Miranda Junior, H. (2019). O trabalho do psicólogo e a verdade na família: ponderações a partir da psicanálise. In Brandão, E. (Org.), Psicanálise e Direito: subversões do sujeito no campo jurídico (pp. 59-94). Rio de Janeiro, RJ: Nau.

Motta, L. E. (2007). Acesso à justiça, cidadania e judicialização no Brasil. Achegas, 36. Recuperado em 22 abr. 2020, de: http://www.achegas.net/numero/36/ eduardo_36.pdf. 
Nunes, C. H. \& Penna, P. (2019). A intervenção judicial pode produzir uma família? In A. Guerra, M. Otoni \& P. Penna (Orgs.), Violências e violações impertinentes: direito e psicanálise IV (pp. 87-102). Belo Horizonte, MG: Scriptum.

Oliveira, D. (2019). O uso da categoria "alienação parental" como "solução" em laudos psicológicos sobre abuso sexual infantil. In Conselho Federal de Psicologia, Debatendo sobre alienação parental: diferentes perspectivas (pp. 161-172). Brasília, DF: CFP.

Quinet, A. (2000). A descoberta do inconsciente: do desejo ao sintoma. Rio de Janeiro, RJ: Zahar.

Quinet, A. (2019). A psicanálise na era trans. In A. Quinet, \& S. Alberti (Orgs.), Sexuação e identidades (pp. 27-37). Rio de Janeiro, RJ: Atos e Divãs.

Sottomayor, M. C. (2011). Uma análise crítica da síndrome de alienação parental e os riscos da sua utilização nos Tribunais de Família. Julgar, 13. Recuperado em 22 abr. 2020, de: <http://julgar.pt/wp-content/uploads/2015/10/073-107Aliena\%C3\%A7\%C3\%A3o-parental.pdf>.

Théry, I. (2007). Novos direitos da criança: a poção mágica? In S. Altoé (Org.), $A$ Lei e as Leis. (pp. 57-78). Rio de Janeiro, RJ: Revinter.

\section{Resumos}

(Family law and psychoanalysis: an approach to parental alienation based on the quantic formulas of sexuation)

Based on the quantic formulas of sexuation, this article describes the contribution of psychoanalysis to the debate of gender issues related to the subject of parental alienation and, in general, to the impasses caused by the judicialization of family relationships. To this end, we perform a literature review of authors who show the relations and differences between the method and the discourse of psychoanalysis on the one hand and, on the other hand, family law. We conclude that psychoanalysis clarifies the tendency of law, governed by the universal of phallic jouissance, to repudiate alterity and singularity inscribed in the field of Other jouissance or feminine jouissance.

Key words: Judicialization, parental alienation, gender, sexuation

(Droit de la famille et psychanalyse : une approche de l'aliénation parentale à partir des formules quantiques de sexuation)

L'objectif de ce travail est de montrer l'apport de la psychanalyse, notamment à partir des formules quantiques de la sexuation, au débat des problèmes de 


\section{LITERATURA, ARTE, CULTURA}

genre associé au thème de l'aliénation parentale et, en général, aux impasses provoquées par la judiciarisation des relations familiales. On propose une révision bibliographique des auteurs montrant les articulations et les différences entre la méthode et le discours de la psychanalyse d'un côté et, de l'autre, le droit de la famille. Pour conclure, on affirme que la psychanalyse éclaire la tendance du droit, régi par l'universel de la jouissance phallique, à rejeter l'altérité et la singularité inscrites dans le champ de la jouissance de l'Autre, soit la jouissance féminine.

Mots clés: Judiciarisation, aliénation parentale,sexe, sexuation

(Derecho de familia y psicoanálisis: un abordaje de la alienación parental desde las fórmulas cuánticas de la sexuación)

El objetivo del presente trabajo es demostrar la contribución del psicoanálisis, especialmente desde las fórmulas cuánticas de la sexuación, al debate de los problemas de género articulados al tema de la alienación parental y, en general, a los sinsabores causados por la judicialización de las relaciones familiares. Para ello, se realiza una revisión bibliográfica de autores que, por un lado, exponen las articulaciones y las diferencias entre el método y el discurso del psicoanálisis, y, por otro lado, el derecho de familia. Se concluye que el psicoanálisis arroja luz sobre la tendencia del derecho, gobernada por lo universal del goce fálico, al repudiar la alteridad y la singularidad inscritas en el campo del goce del Otro o del goce femenino.

Palabras clave: Judicialización, alienación parental, género, sexuació

Citação/Citation: Brandão, E. (2021, março). Direito de família e psicanálise: uma abordagem da alienação parental a partir das fórmulas quânticas da sexuação. Revista Latinoamericana de Psicopatologia Fundamental, 24(1), 200-218. http://dx.doi.org/10.1590/ 1415-4714.2021v24n1p200.11.

Editora/Editor: Profa. Dra. Sonia Leite

Submetido/Submitted: 26.4.2020 / 4,26.2020 Aceito/Acepted: 10.8.2020/8.10.2020

Copyright: ( 2009 Associação Universitária de Pesquisa em Psicopatologia Fundamental/ University Association for Research in Fundamental Psychopathology. Este é um artigo de livre acesso, que permite uso irrestrito, distribuição e reprodução em qualquer meio, desde que o autor e a fonte sejam citados / This is an open-access article, which permits unrestricted use, distribution, and reproduction in any medium, provided the original authors and sources are credited. 
Financiamento/Funding: Este trabalho não recebeu apoio / This work received no funding.

Conflito de interesses/Conflict of interest: $\mathrm{O}$ autor declara que não há conflito de interesses. / The author declares that there is no conflict of interest.

\section{Eduardo Ponte Brandẽo}

Doutor em Teoria Psicanalítica pela Universidade Federal do Rio de Janeiro - UFRJ (Rio de Janeiro, RJ, Br), com Pós-Doutorado em Psicanálise, Saúde e Sociedade pela Universidade Veiga de Almeida - UVA (R|io de Janeiro, RJ, Br); Mestre em Psicologia Clínica pela Pontifícia Universidade Católica do Rio de Janeiro - PUC-Rio (Rio de Janeiro, RJ, Br); Coordenador do curso de pós-graduação lato sensu em Psicologia Jurídica AVM/UCAM (Rio de Jasneiro, RJ, Br). Psicólogo do Tribunal de Justiça/RJ.

Rua Senador Euzébio 25/402 - Flamengo

22250-080 Rio de Janeiro, RJ, Br

eduardopbrandao@gmail.com

https://orcid.org/0000-0003-3773-6575

This is an open-access article, which permits unrestricted use, distribution, the original authors and sources are credited. 